\title{
Maspin and MCM2 immunoprofiling in salivary gland carcinomas
}

Shaimaa E Ghazy, Iman M Helmy* and Houry M Baghdadi

\begin{abstract}
Background: The pathogenesis of salivary gland carcinomas is very complex and prognostic markers are difficult to find in these carcinomas of which the different subtypes have varying malignant potential. The study was conducted to examine the cellular distribution of maspin and MCM2 in salivary gland carcinomas and their value to predict lymph node metastasis.

Materials and methods: Fifty three paraffin blocks of different lesions (15 muco-epidermoid carcinoma, 14 adenoid cystic carcinoma, 3 epi-myoepithelial carcinoma, 5 salivary duct carcinoma, 5 malignant pleomorphic adenoma, 6 polymorphous low grade adenocarcinoma and 5 acinic cell carcinoma) were prepared for immunohistochemical staining with maspin and MCM2 antibodies. ANOVA and Pearson correlation tests were used for the statistical analysis of the results.

Results: All salivary gland carcinomas express maspin and MCM2 with variable cellular localization. There was a significant difference in the expression of each antibody between mucoepidermoid carcinoma, adenoid cystic carcinoma and polymorphous low grade adenocarcinoma. No association was found between examined markers and lymph node metastasis.

Conclusions: Salivary gland carcinomas express maspin and MCM2 with variable levels and cellular localization, consisting important markers of biological behavior in these tumors. The level of MCM2 expression can be used in the differential diagnosis of adenoid cystic carcinoma and polymorphous low grade adenocarcinoma. Further study with large sample size is recommended to assess their value in prediction of lymph node metastasis.
\end{abstract}

Keywords: Maspin, MCM2, salivary gland carcinomas

\section{Introduction}

Salivary gland neoplasms which comprise about $5 \%$ of head and neck cancers are a morphologically and clinically diverse group of lesions and may present considerable diagnostic challenge to the pathologist [1]. The most frequent salivary gland carcinoma types are mucoepidermoid carcinoma, adenoid cystic carcinoma, acinic cell carcinoma, malignant pleomorphic adenoma and salivary duct carcinoma [2].

Mammary Serine Protease Inhibitor (maspin) belongs to the serine protease inhibitor (serpin) family $[3,4]$, which comprises a large protein family with diverse biological functions [5]. There is a controversy about maspin protease inhibition; Sheng et al [6] stated that maspin has

\footnotetext{
* Correspondence: imanhelmy373@hotmail.com

Oral Pathology Department, Faculty of Dentistry, Ain Shams University, Cairo, Egypt
}

\section{Biomed Central}

(c) 2011 Ghazy et al; licensee BioMed Central Ltd. This is an Open Access article distributed under the terms of the Creative Commons Attribution License (http://creativecommons.org/licenses/by/2.0), which permits unrestricted use, distribution, and reproduction in any medium, provided the original work is properly cited. protease inhibitory activity. On the contrary, Bass et al [7] reported that maspin has no protease inhibitory properties.

Maspin expression has been demonstrated in multiple tissues including epithelium of the breast, prostate, lung and in stromal cells of the cornea [8-10]. Maspin demonstrates broad localization patterns [5], in mammary epithelial cells, maspin localizes primarily to the cytoplasm, but can also localize to the nucleus, and the cell surface [11].

One of the first regulatory mechanisms identified for maspin involved p53 signaling. The regulation of maspin by p 53 could explain the role of p53 in cell invasion and metastasis and hypothesizes that cancer cells expressing mutant p53 would be more likely to metastasize, in part due to the inability to upregulate the maspin gene [5]. In addition, increased maspin was associated with an increase in apoptosis and a reduction in cell invasion. This effect 
was blocked by the addition of a maspin-blocking antibody [12].

Recent study has also established a role for the common breast cancer drug Tamoxifen (TAM) in regulating the expression of maspin [5]. The clinical efficacy of TAM has been attributed to growth arrest and induction of apoptosis in breast cancer cells. TAM was shown to induce maspin expression in vitro and in situ [13]. Also, it was suggested that maspin has an inhibitory effect on tumor induced angiogenesis [14], cell motility, invasion and metastasis [15]. Extensive studies have been undertaken to determine the mechanisms employed by maspin to produce its anti-metastatic effects. One line of evidence suggests that maspin regulates cell invasion by altering the integrin profile of the cell [5]. In support of a cell surface event, it has been reported that cell surfaceassociated maspin is primarily responsible for its antiinvasive properties [16].

Several reports indicated that maspin can function as an inhibitor of angiogenesis. Both rMaspin and secreted maspin can impede the migration of cultured endothelial cells toward bFGF and VEGF which act as important chemo-attractants during angiogenesis. Also, maspin was shown to effectively block neovascularization and reduce the density of the neoplasm-associated microvessels in vivo $[17,18]$. Solomon et al [19] reported that neoplasms with both cytoplasmic and nuclear maspin expression had lower VEGF and cyclooxygenase-2 (COX-2) expression than neoplasms with cytoplasmic maspin expression only, so suppression of VEGF by maspin may thus occur through a COX-2 mediated pathway.

In addition to its anti-angiogenic properties, maspin has also been implicated in apoptosis [5]. It has been demonstrated that maspin sensitizes breast cancer cells to staurosporine (STS)-induced apoptosis [20]. Staurosporine is a synthetic chemical known to induce apoptosis via an intrinsic pathway [21]. The apoptotic effect of maspin appears to be tumor-specific since normal epithelial cells that express maspin at a high level are not sensitized to drug-induced apoptosis [22].

The ubiquitous localization of maspin (cytoplasmic, nuclear, cell surface-associated, secreted) suggests that maspin may be involved in multiple pathways and processes. Loss of maspin has been associated with poor prognosis in various malignant neoplasms like ovarian cancer, oral squamous cell carcinoma, lung and prostate cancer [23-25].

The MCM (minichromosome maintance) proteins identify a group of ten conserved factors functioning in the replication of the genome of eukaryotic organisms [26]. Among these, MCM2-7 proteins are related to each other and form a complex implicated at the initiation step of DNA synthesis. MCM2-7 act as licensing factors for DNA replication to ensure that the genome is replicated only once in each cell cycle [26,27].

Since MCM activity is essential for DNA replication in dividing cells and is lost in quiescence [28], MCMs are obvious markers for proliferation [26]. Molecular studies suggested that increased levels of MCMs mark not only proliferative malignant cells, but also precancerous cells and the potential for recurrence [29,30]. In breast cancers, increasing neoplasm grade is associated with increased MCM2 expression [31]. Thus, they may prove to be effective markers for diagnosis of neoplasms [26].

Several studies reported that MCM2 and Ki-67 are both markers of cellular proliferation and required for cell cycle progression [32]. They showed that anti-MCM2 antibody stained a larger number of cells than anti Ki-67, suggesting that Ki-67 may be expressed during a shorter interval of the cell cycle than MCM2 [33]. MCM2 is present throughout the four phases of cell cycle [31], while Ki-67 is predominantly expressed during S, G2 and M phases. The present study aimed to evaluate the expression of maspin and MCM2 in salivary gland carcinomas and their value to predict lymph node metastasis.

\section{Materials and methods}

The material of this study consisted of 53 formalin-fixed, paraffin-embedded specimens of malignant salivary gland neoplasms, all collected from the archives of the General Pathology Department, Faculty of Medicine, Ain Shams University and National Cancer Institute, Cairo University. Fifteen cases of mucoepidermoid carcinoma (MEC), 10 of which were diagnosed as high grade and the other 5 cases as low grade, 14 cases of adenoid cystic carcinoma (ADCC), 5 cases of salivary duct carcinoma (SDC), 3 cases of epi-myoepithelial carcinoma (EMC), 5 cases of malignant pleomorphic adenoma (MPA), 6 cases of polymorphous low-grade adenocarcinoma (PLGA) and 5 cases of acinic cell carcinoma (ACC). Clinical information about lymph node metastasis was obtained from patients' medical records (summary of cases is displayed in table 1). For all specimens five micrometer thick sections were prepared and stained with hematoxylin and eosin to confirm the diagnosis.

In summary, immunohistochemical staining is performed as follows: the tissues were deparaffinized in xylene and hydrated through graded alcohol and washed with tap water. Based on the manufacturers' recommendation, the slides were transferred for antigen retrieval. The slides were washed with phosphate buffer and separately incubated with maspin (Visionbiosystems Novocastra ${ }^{\mathrm{TM}}$ Laboratories, Ltd, United Kingdom) diluted at a ratio of 1:30 and MCM2 (Lab Vision Corporation, USA) diluted at a ratio of 1:50 over-night. The slides were then washed again in PBS and incubated with biotinylated antibody for 
Table 1 Types of cases and association with lymph node metastasis of the selected cases

\begin{tabular}{lcc}
\hline $\begin{array}{l}\text { Malignant Salivary } \\
\text { Gland Neoplasms }\end{array}$ & Total Number of cases & $\begin{array}{c}\text { Number of cases } \\
\text { Associated with lymph node } \\
\text { metastasis }\end{array}$ \\
\hline MEC & 15 & 4 (high grade variant) \\
\hline ADCC & 14 & 4 (2 of solid type and 2 of cribriform type) \\
\hline EMC & 3 & - \\
\hline SDC & 5 & 2 \\
\hline M PA & 5 & - \\
\hline PLGA & 6 & - \\
\hline ACC & 5 & 11 \\
\hline Total & 53 & 11 \\
\hline
\end{tabular}

30 minutes, and then were washed in PBS. Finally, the slides were incubated with peroxidase labeled streptavidin for 30 minutes and washed in PBS. Subsequently, DAB chromogen was applied for antibody staining (brown). The samples were then allowed to react with Mayer's hematoxylin for 5 minutes, dehydrated and covered with cover glass.

For each positive section, 6 microscopic fields showing highest immunopositivity were selected and photomicrographs were captured at original magnification $40 \times$. This was performed using a digital camera (C5060, Olympus, Japan) mounted by a C-mount to a light microscope (BX60, Olympus, Japan). All the steps for immunohistochemical evaluation were carried out using image analysis software (Image J, 1.41a, NIH, USA). The area fraction (AF) of the positive cells was calculated automatically. The area fraction represented the percentage of immunopositive area to the total area of the microscopic field. The collected data was tabulated in an excel sheet and statistically analyzed using SPSS 15.

\section{Results}

All cases of MEC demonstrated maspin immunoreactivity. Most of the epidermoid cells in the cases diagnosed as high grade were negative for maspin, with a few positive cells in which the reaction was cytoplasmic. The mucoussecreting cells showed membranous staining. Low grade MEC showed more positive cells with nuclear and cytoplasmic staining of the epidermoid cells (Figure 1a). Concerning MCM2, most of the epidermoid cells revealed cytoplasmic staining in high grade cases (Figure 2a), while in low grade cases, little number of epidermoid cells were positive.

In ADCC, 12 cases of cribriform pattern demonstrated cytoplasmic maspin and MCM2 staining (Figure 1b, 2b). Two cases of solid pattern were negative for maspin but revealed cytoplasmic reaction for MCM2. Myoepithelial cells were negative for both antibodies.

In EMC, the neoplastic cells demonstrated cytoplasmic and nuclear (either the whole nucleus or confined only to the nuclear membrane) maspin staining and cytoplasmic MCM2 staining (Figure 1c, 2c). Few neoplastic cells were negative for maspin and MCM2.

In SDC, cases with solid and papillary pattern showed cytoplasmic maspin and MCM2 reaction (Figure 1d, 2d). In cribriform pattern with comedo necrosis, little nuclear and mainly cytoplasmic maspin reaction was detected, while MCM2 revealed cytoplasmic reaction only.

In MPA, all cases revealed nuclear and cytoplasmic maspin and MCM2 reaction in epithelial and some myoepithelial cells (Figure 1e, 2e), but in PLGA, there was cytoplasmic reaction for both antibodies in neoplastic cells arranged in cribriform and cystic pattern (Figure 1f, 2f). In ACC, one case of clear cell variant demonstrated membranous maspin and MCM2 reaction, while the remaining cases showed nuclear and cytoplasmic reaction for both antibodies (Figure 1g, 2g).

Statistically, ANOVA test revealed significant difference in the expression of both markers between MEC, ADCC and PLGA $(P$ value $=0.000)($ table 2,3$)$. Results of Post Hoc test for maspin and MCM2 expression are shown in table 4 and 5 respectively. Pearson's correlation analysis revealed no significant correlation between both maspin or MCM2 expression and lymph node metastasis.

\section{Discussion}

Salivary gland neoplasms are a relatively rare and morphologically diverse group of lesions. A diagnosis based on hematoxylin and eosin stained sections remains the gold standard in salivary gland pathology [1].

Several studies were performed to detect the expression of maspin protein in different malignant neoplasms such as ovarian carcinoma, oral squamous cell carcinoma, pulmonary adenocarcinoma and prostate carcinoma to clarify its role in malignancy. Most researchers found that the increased maspin expression does correlate with better prognosis in these neoplasms [19,23-25].

Recent studies have proposed that MCM proteins may be sensitive proliferation markers and may serve as novel biomarkers for prognostication and diagnosis of various 


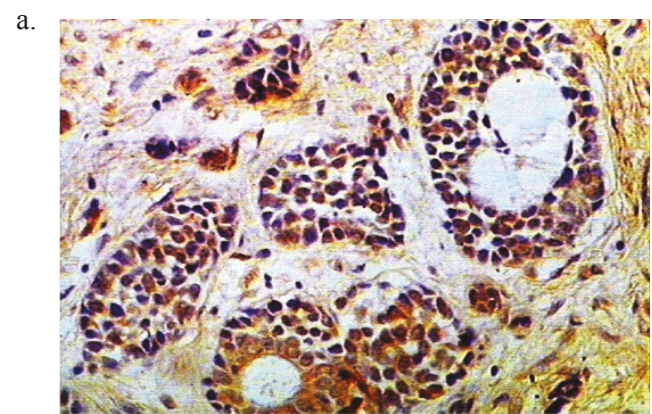

b

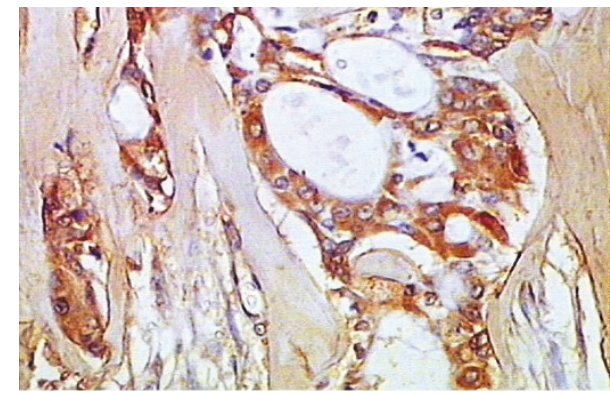

c.

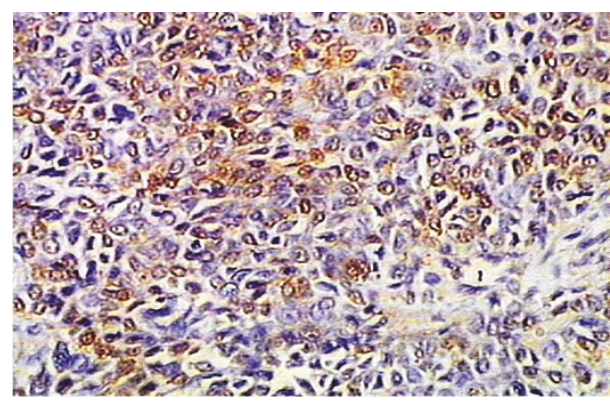

d

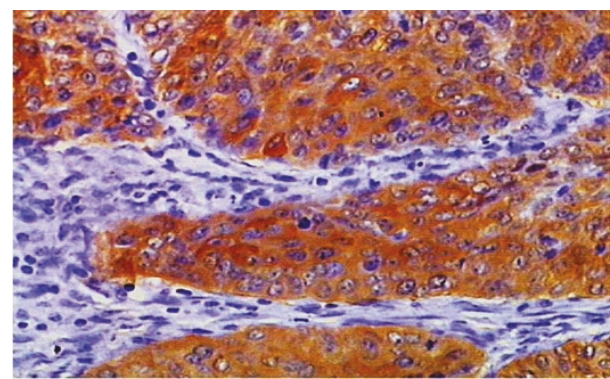

e.

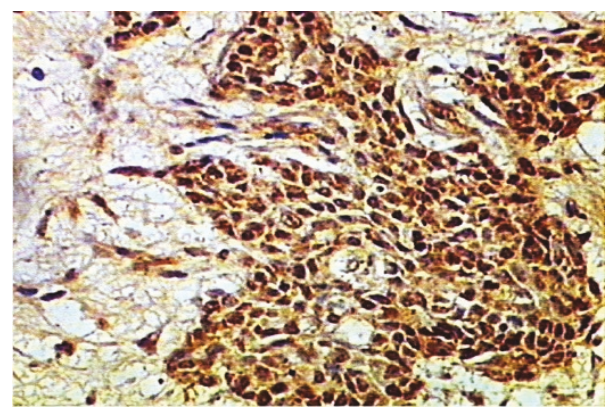

f.

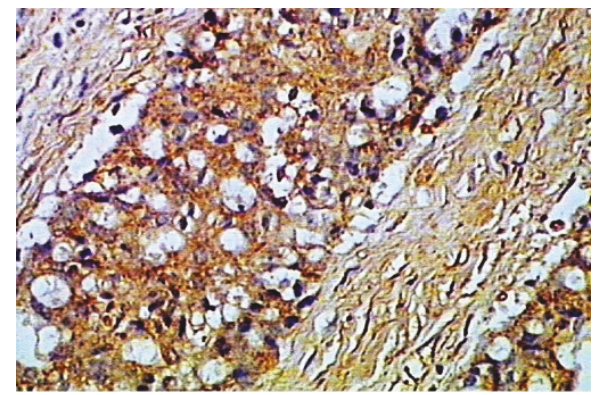

g

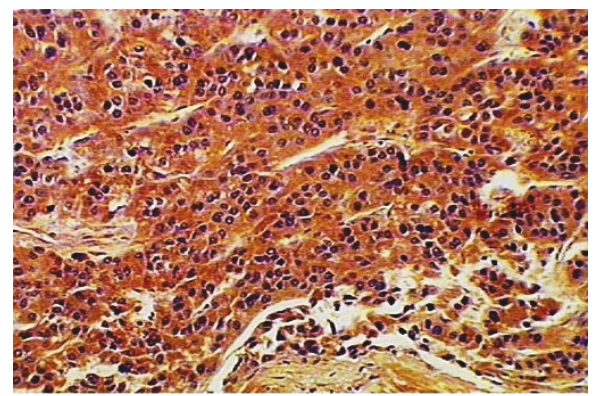

Figure 1 Maspin expression patterns in salivary gland carcinomas. a: low grade MECx200. b: ADCCx200. C: EMCx200. d: SDCx200. e: MPAx200. f: PLGAx200. g: ACCx100.

premalignant and malignant lesions $[31,34,35]$. The superior sensitivity of the MCM proteins over the standard proliferation markers such as Ki-67 resides in the fact that MCMs identify not only cycling cells, but also non-cycling cells with proliferative potential [35].
High grade MEC is characterized by decreased maspin expression. Loss or decreased expression of maspin indicates loss of its role in inhibition of tumor invasion, metastasis and angiogenesis [3]. Evidence of both nuclear and cytoplasmic maspin expression was observed in low 
a.

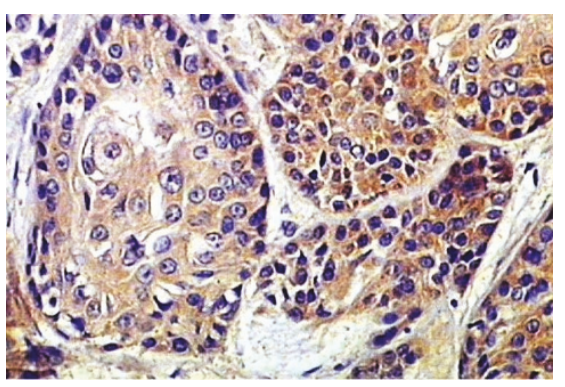

b.

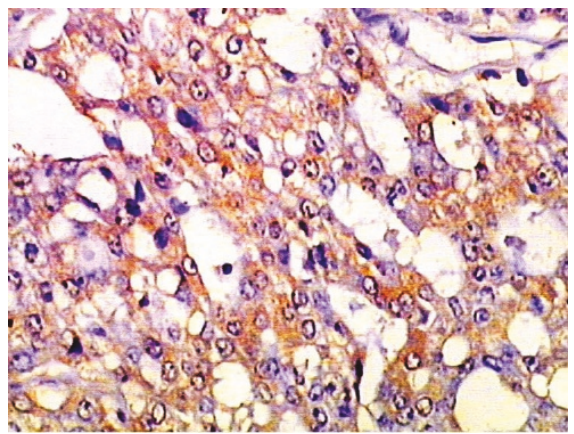

c.

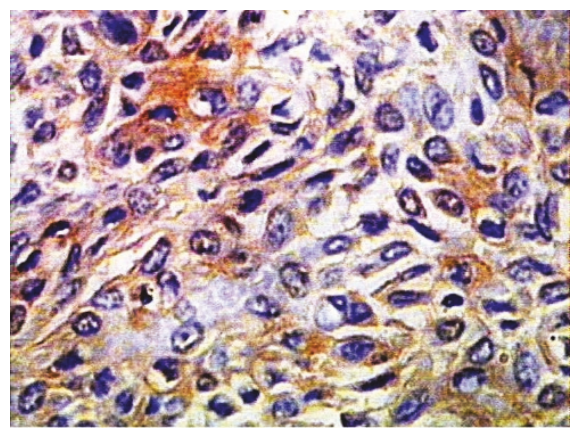

d.

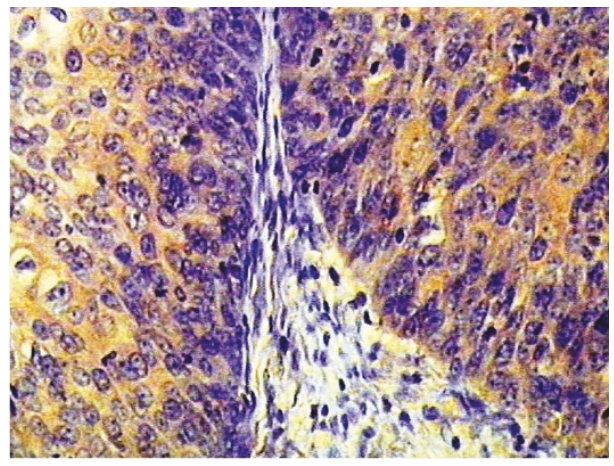

e.

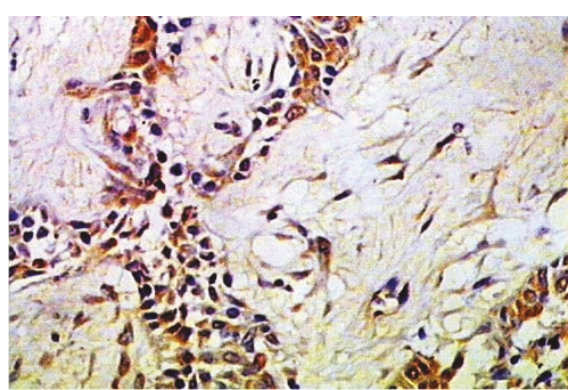

f.

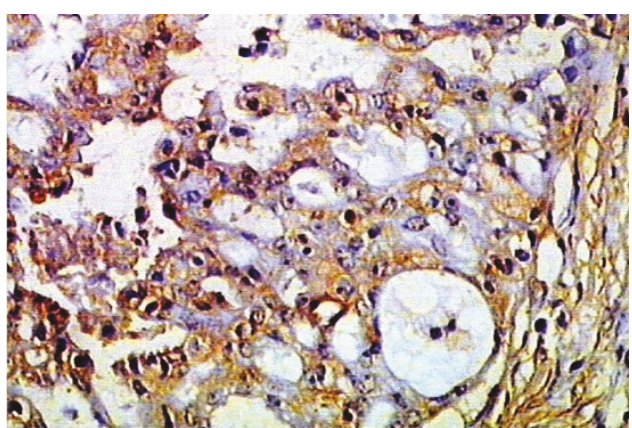

g.

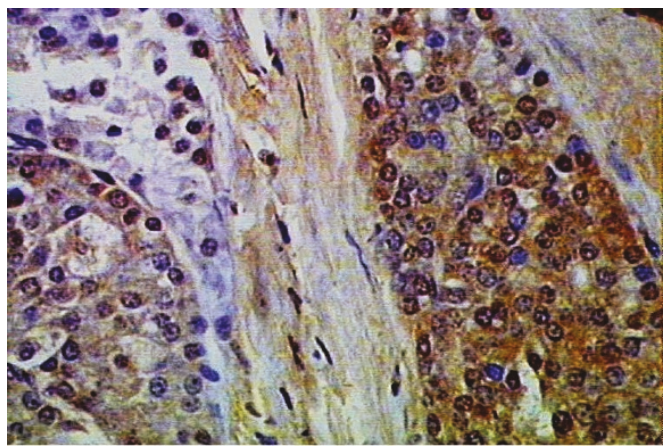

Figure 2 MCM2 expression patterns in salivary gland carcinomas. a: high grade MECx200. b: ADCCX200. c: EMCX400. d: SDCX200. e: MPAx200. f: PLGAX200. g: ACCX400.

grade MEC; this finding denotes that maspin cellular localization has an influence on its role as tumor suppressor gene [5]. Sood et al [36] demonstrated that mixed nuclear and cytoplasmic maspin localization in ovarian cancer is indicative of a more benign lesion than neoplasms with cytoplasmic expression only, suggesting an important tumor-suppressive role for nuclear maspin. This maspin nuclear localization pattern had been seen 
Table 2 ANOVA for maspin

\begin{tabular}{lccccc}
\hline \multicolumn{5}{c}{ ANOVA } \\
MEAN AF & Sum of Squares & df & Mean Square & F & Sig. \\
\hline Between Groups & 3682.051 & 2 & 1841.026 & 683.744 & .000 \\
Within Groups & 80.777 & 30 & 2.693 & & \\
Total & 3762.828 & 32 & & \\
\hline
\end{tabular}

in other neoplasms as well, including non-small cell lung carcinoma and pancreatic cancer, where predominantly nuclear maspin is associated with favorable morphologic features $[11,24]$.

The high grade MEC cases showed a marked increase of MCM2 expression when compared to the low grade cases, which was also in agreement with Vargas et al [34]. This might be explained by the fact that in cancer, differentiated neoplastic cells tend to grow and spread at a slower rate than undifferentiated or poorly differentiated cells, which lack the structure and function of normal cells and grow uncontrollably [37]. It was stated that withdrawal of cells from the cell cycle into differentiated state is coupled with downregulation of MCM2 expression [31,35].

In ADCC, cases with solid pattern were maspin immunonegative, which was in agreement with Navarro et al [15] and indicates the aggressive behavior of this pattern. Maass et al [38] stated that maspin is lost in the metastatic cells, and Shwarz et al [3] reported in his study that in intermediate grade tumours (ADCC, MEC, carcinoma expleomorphic adenoma) loss of maspin expression, mainly localized to the nucleus, was associated with lymph node metastases.

Myoepithelial cells in ADCC were maspin immunonegative. This result was in agreement with Navarro et al [15]. Normally maspin is expressed in high amounts in myoepithelial cells and it was suggested that maspin can be used as a myoepithelial cell marker [39]. Thus, loss of maspin in this cell might indicate the role of myoepithelial cells in malignant transformation and histogenesis of this neoplasm [40].

Adenoid cystic carcinoma demonstrated high value of MCM2 expression; this finding gives an impression of the high proliferative power of ADCC. This result was consistent with previous study denoting that ADCC is a highly proliferative salivary gland neoplasm [34].
Myoepithelial carcinoma showed the smallest value of maspin expression, and high value of MCM2 expression. These values might indicate the aggressive behavior of this neoplasm. The knowledge of myoepithelial carcinoma behavior and the optimal line of management are deficient, possibly due to its rare occurrence and the lack of comprehensive reports of large case series [41]. However, some authors describe myoepithelial carcinoma by infiltrative growth and potential metastasis $[2,41,42]$.

Salivary duct carcinoma revealed the highest value of MCM2 expression and reduced maspin expression; this finding confirms the high grade behavior of this tumor [43].

Malignant pleomorphic adenoma possessed the highest value of maspin expression and low MCM2 expression, this is in accordance with Umekita et al [44] who observed that high maspin expression in breast carcinoma was associated with poor prognosis, and this was explained by genetic alteration at the maspin gene locus contributing to the loss of tumor suppressing function of the maspin protein. Values of maspin and MCM2 expression in PLGA and ACC reflected low grade nature of these tumors which are characterized by a low metastatic potential and a high survival rate [2].

The differential diagnosis of both ADCC and PLGA is of a great interest as both share common histopathological features and may cause diagnostic difficulty particularly in small biopsies [1]. Our data demonstrated that ADCC has a higher proliferation power compared to PLGA as determined by MCM2 immunostaining. This result was in conformity with Vargas et al [34] who support the idea that proliferation markers can be used to differentiate borderline cases.

No significant correlation between maspin expression and lymph node metastasis was found in this study. This finding disagrees with Schwarz et al [3] who reported that lack of maspin expression was significantly correlated with

Table 3 ANOVA for MCM2

\section{ANOVA}

MEAN AF

\begin{tabular}{lccccc}
\hline & Sum of Squares & df & Mean Square & F & Sig. \\
\hline Between Groups & 713.006 & 2 & 356.503 & 39.753 & .000 \\
Within Groups & 286.978 & 32 & 8.968 & & \\
Total & 999.984 & 34 & & \\
\hline
\end{tabular}


Table 4 Post Hoc Test for maspin

Multiple Comparisons

MEAN AF

Tukey HSD

\begin{tabular}{llccccc}
\hline (I) type of lesion & (J) type of lesion & Mean Difference (I-J) & Std. Error & Sig. & \multicolumn{2}{c}{$\begin{array}{c}\text { 95\% Confidence Interval } \\
\text { Lpper Bound }\end{array}$} \\
\hline MEC & adcc & $-9.40967^{*}$ & .63552 & .000 & -10.9764 & -7.8429 \\
& Poly LG AdenoCa & $-29.27800^{*}$ & .79263 & .000 & -31.2321 & -27.3239 \\
\hline adcc & MEC & $9.40967^{*}$ & .63552 & .000 & 7.8429 & 10.9764 \\
& Poly LG AdenoCa & $-19.86833^{*}$ & .82045 & .000 & -21.8910 & -17.8457 \\
\hline Poly LG AdenoCa & MEC & $29.27800^{*}$ & .79263 & .000 & 27.3239 & 31.2321 \\
& adcc & $19.86833^{*}$ & .82045 & .000 & 17.8457 & 21.8910 \\
\hline
\end{tabular}

*. The mean difference is significant at the 0.05 level.

Table 5 Post Hoc Test for MCM2

\begin{tabular}{|c|c|c|c|c|c|c|}
\hline \multicolumn{7}{|c|}{ Multiple Comparisons } \\
\hline \multirow[t]{2}{*}{ (I) type of lesion } & \multirow[t]{2}{*}{ (J) type of lesion } & \multirow[t]{2}{*}{ Mean Difference (I-J) } & \multirow[t]{2}{*}{ Std. Error } & \multirow[t]{2}{*}{ Sig. } & \multicolumn{2}{|c|}{ 95\% Confidence Interval } \\
\hline & & & & & Lower Bound & Upper Bound \\
\hline \multirow[t]{2}{*}{$\overline{M E C}$} & $\operatorname{adcc}$ & -2.52957 & 1.11285 & .074 & -5.2643 & .2051 \\
\hline & Poly LG AdenoCa & $10.35900^{*}$ & 1.44656 & .000 & 6.8043 & 13.9137 \\
\hline \multirow[t]{2}{*}{$\operatorname{adcc}$} & MEC & 2.52957 & 1.11285 & .074 & -.2051 & 5.2643 \\
\hline & Poly LG AdenoCa & $12.88857^{*}$ & 1.46125 & .000 & 9.2977 & 16.4794 \\
\hline \multirow[t]{2}{*}{ Poly LG AdenoCa } & MEC & $-10.35900^{*}$ & 1.44656 & .000 & -13.9137 & -6.8043 \\
\hline & adcc & $-12.88857^{*}$ & 1.46125 & .000 & -16.4794 & -9.2977 \\
\hline
\end{tabular}

*. The mean difference is significant at the 0.05 level.

positive lymph node metastasis. This might be due to the small sample size used in this study in which only 11 cases were associated with positive lymph node metastasis.

Also, there was no significant correlation between MCM2 expression and positive lymph node metastasis. This result was in agreement with Vargas et al [34] and was dissimilar to Guzinska-Ustymowiczi et al study [45] in which MCM2 over expression was associated with lymph node metastasis.

Maspin and MCM2 are important markers of biological behavior in salivary gland carcinomas. Further study with large sample size is required to clarify the correlation between maspin and MCM2 expression and lymph node metastasis.

\footnotetext{
Authors' contributions

SE participated in collection of data and references, immunohistochemical staining and evaluation by image analysis. $\mathrm{IH}$ participated in the design of the study, performed the statistical analysis and drafted the manuscript. HB participated in the design and coordination, sequence alignment and reviewing the manuscript. All authors read and approved the final manuscript.
}

\section{Competing interests}

The authors declare that they have no competing interests.
Received: 25 June 2011 Accepted: 26 September 2011 Published: 26 September 2011

\section{References}

1. Speight P, Barrett A: Salivary gland tumors. Oral Dis 2002, 8:229-240.

2. Barnes L, Eveson J, Reichart P, Sidransky D: Salivary glands. In Pathology and genetics of head and neck tumors. Edited by: Barnes L. Lyon: IARC Press; 2005:212-213.

3. Schwarz S, Ettl T, Kleinsasser K, Hartmann A, Reichert T, Driemel O: Loss of maspin expression is a negative prognostic factor in common salivary gland tumors. Oral Oncol 2008, 44:563-570.

4. Xia W, Lau Y, Hu M, Li L, Johnston D, Sheng S, El-Naggar A, Hung M: High tumoral maspin expression is associated with improved survival of patients with oral squamous cell carcinoma. Oncogene 2000, 19:2398-2403.

5. Bailey C, Khalkhali-Ellis Z, Seftor E, Hendrix M: Biological functions of maspin. J Cell Physi 2006, 209:617-624.

6. Sheng S, Truong B, Fredrickson D, Wu R, Pardee A, Sager R: Tissue-type plasminogen activator is a target of the tumor suppressor gene maspin. Proc Natl Acad Sci 1998, 95:499-504.

7. Bass R, Fernandez A, Ellis V: Maspin inhibits cell migration in the absence of protease inhibitory activity. J Biol Chem 2002, 277:46845-46848.

8. Ngamkitidechakul C, Burke J, O'Brien W, Twining S: Maspin: synthesis by human cornea and regulation of in vitro stromal cell adhesion to extracellular matrix. Invest Ophthalmol Vis Sci 2001, 42:3135-3141.

9. Reis-Filho J, Torio B, Albergaria A, Schmitt F: Maspin expression in normal skin and usual cutaneous carcinomas. Virchows Arch 2002, 441:551-558.

10. Yatabe Y, Mitsudomi T, Takahashi T: Maspin expression in normal lung and non-small cell lung cancers: cellular property-associated expression under the control of promoter DNA methylation. Oncogene 2004, 23:4041-4049. 
11. Nicolai M, Martin Z, Koichi N, Pierre R: Maspin locates to the nucleus in certain cell types. J Pathol 2002, 197:274-275.

12. Khalkhali-Ellis Z, Hendrix M: Nitric oxide regulation of maspin expression in normal mammary epithelial and breast cancer cells. Am J Pathol 2003, 162:1411-1417.

13. Mandlekar S, Kong A: Mechanism of tamoxifen induced apoptosis. Apoptosis 2001, 6:469-477.

14. Cher M, Biliran H, Bhagat S, Meng Y, Che M, Lockett J, Abrams J, Fridman R, Zachareas M, Sheng S: Maspin expression inhibits osteolysis, tumor growth and angiogenesis in a model of prostate cancer bone metastasis. Proc Natl Acad Sci 2003, 100:7847-7852.

15. Navarro R, Martins M, de Arau' jo V: Maspin expression in normal and neoplastic salivary gland. J Oral Pathol Med 2004, 33:435-440.

16. Sheng S, Carey J, Seftor E, Dias L, Hendrix M, Sager R: Maspin acts at the cell membrane to inhibit invasion and motility of mammary and prostatic cancer cells. Proc Natl Acad Sci 1996, 93:11669-11674.

17. Nickoloff $B$, Lingen $M$, Chang B, Shen $M$, Swift M, Curry J, Bacon P, Bodner B, Roninson I: Tumor suppressor maspin is up-regulated during keratinocyte senescence, exerting a paracrine antiangiogenic activity. Cancer Res 2004, 64:2956-2961.

18. Zhang M, Volpert $\mathrm{O}$, Shi $Y$, Bouck $N$ : Maspin is an angiogenesis inhibitor. Nat Med 2000, 6:196-199.

19. Solomon L, Munkarah A, Schimp V, Arabi M, Morris R, Nassar H, Ali-Fehmi R: Maspin expression and localization impact on angiogenesis and prognosis in ovarian cancer. Gynecol Oncol 2006, 101:385-389.

20. Jiang N, Meng Y, Zhang S, Mensah-Osman E, Sheng S: Maspin sensitizes breast carcinoma cells to induced apoptosis. Oncogene 2002, 21:4089-4098

21. Duan S, Hajek P, Lin C, Shin S, Attardi G, Chomyn A: Mitochondrial outer membrane permeability change and hypersensitivity to digitonin early in staurosporine-induced apoptosis. J Biol Chem 2003, 278:1346-1353.

22. Sheng S: A role of novel serpin maspin in tumor progression: the divergence revealed through efforts to converge. J Cell Physi 2006, 209:631-635.

23. Yasumatsu R, Nakashima T, Hirakawa N, Kumamoto Y, Kuratomi K, Tomita K, Komiyama S: Maspin expression in stage I and II oral tongue squamous cell carcinoma. Head Neck 2001, 23:962-966.

24. Lonardo F, Li X, Siddiq F, Singh R, Al-Abbadi M, Pass H, Sheng S: Maspin nuclear localization is linked to favorable morphological features in pulmonary adenocarcinoma. Lung Cancer 2006, 51:31-39.

25. Stefan $M$, Jürgen $S$, Carsten B, Wolfgang $B$, Antje $M$, Christian $K$, Jörg $H$, Ruth K, Masahiko K, Udo J, Markus K: Expression of the p53 and maspin protein in primary prostate cancer: correlation with clinical features. Int $J$ Cancer 2001, 95:337-342.

26. Forsburg S: Eukaryotic MCM proteins: beyond replication initiation. Microbiol Mol Biol Rev 2004, 68:109-131.

27. Blow J, Dutta A: Preventing re-replication of chromosomal DNA. Nat Rev Mol Biol 2005, 6:476-486.

28. Madine M, Swietlik M, Pelizon C, Romanowski P, Mills A, Laskey R: The roles of the MCM, ORC and Cdc6 proteins in determining the replication competence of chromatin in quiescent cells. J Struct Biol 2000, 129:198-210.

29. Going J, Keith W, Neilson L, Stoeber K, Stuart R, Williams G: Aberrant expression of minichromosome maintenance proteins 2 and 5 and Ki-67 in dysplastic squamous esophageal epithelium and Barrett's mucosa. Gut 2002, 50:373-377.

30. Alison M, Hunt T, Forbes S: Minichromosome maintenance (MCM) proteins may be pre-cancer markers. Gut 2002, 50:290-291.

31. Fanshawe T, Prevost A, Sainsbury R, Williams G, Stoeber K: DNA replication licensing and cell cycle kinetics of normal and neoplastic breast. Brit J Cancer 2005, 93:1295-1300.

32. Lei $M$, Tye $B$ : Initiating DNA synthesis: from recruiting to activating the MCM complex. J Cell Sci 2001, 14:1447-1454.

33. Tan D, Huberman J, Hyland A, Loewen G, Brooks J, Beck A, Todorov I, Bepler G: MCM2 a promising marker for premalignant lesions of the lung: a cohort study. BMC Cancer 2001, 1:1-6.

34. Vargas P, Cheng W, Barrett A, Craig G, Speight P: Expression of Mcm-2, Ki67 and geminin in benign and malignant salivary gland tumors. J Oral Pathol Med 2008, 37:309-318.
35. Stoeber K, Tlsty T, Happerfield L, Thomas G, Romanov S, Bobrow L, Williams E, Williams G: DNA replication, licensing and human cell proliferation. J Cell Sci 2001, 114:2027-2041.

36. Sood A, Fletcher M, Gruman L, Coffin J, Jabbari S, Khalkhali-Ellis Z, Arbour N,

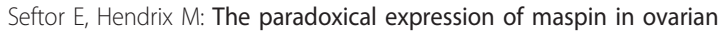
carcinoma. Clin Cancer Res 2002, 8:2924-2932.

37. Yamaguchi N, Ito E, Azuma S, Honma R, Yanagisawa Y, Nishikawa A Kawamura M, Imai J, Tatsuta K, Inoue K, Semba K, Watanabe S: Fox A1 as a lineage-specific oncogene in luminal type breast cancer. Biochem Biophys Res Commun 2008, 365:711-717.

38. Maass N, Teffner M, Rosel F, Pawaresch R, Jonat W, Nagasaki K, Rudolph P: Decline in the expression of the serine proteinase inhibitor maspin is associated with tumor progression in ductal carcinomas of the breast. J Pathol 2001, 195:321-326.

39. Reis-Filho J, Milanezi F, Silva P, Schmitt F: Maspin expression in myoepithelial tumors of the breast. Pathol Res Pract 2001, 197:817-821.

40. Takahashi S, Nakamura S, Shinzato K, Domon T, Yamamoto T, Wakita M: Apoptosis and proliferation of myoepithelial cells in atrophic rat submandibular glands. J Histochem Cytochem 2000, 49:1557-1564.

41. Wang Z, Herrington B, Schwartz M, Laucirica R: Myoepithelial carcinoma of the parotid gland metastatic to the kidney: case report and review of the literature. Diag Cytopathol 2010, 38(suppl 4):279-282.

42. Savera A, Sloman A, Huvos A, Klimstra D: Myoepithelial carcinoma of the salivary glands: a clinicopathologic study of 25 patients. Am J Surg Pathol 2000, 24:761-774.

43. Jaehne M, Roeser K, Jaekel T, Schepers J, Albert N, Loning T: Clinical and immunohistologic typing of salivary duct carcinoma: a report of 50 cases. Cancer 2005, 103:2526-33.

44. Umekita $Y$, Ohi $Y$, Sagara $Y$, Yoshida H: Expression of maspin predicts poor prognosis in breast cancer patients. Int J Cancer 2002, 100:452-455.

45. Guzinska-Ustymowiczi K, Pryczyiczi A, Kemonai A, Czyzewska J: Correlation between proliferation markers: PCNA, Ki-67, MCM-2 and antiapoptotic protein BCl-2 in colorectal cancer. Anticancer Res 2009, 29:3049-3052.

doi:10.1186/1746-1596-6-89

Cite this article as: Ghazy et al:: Maspin and MCM2 immunoprofiling in salivary gland carcinomas. Diagnostic Pathology 2011 6:89.

\section{Submit your next manuscript to BioMed Central and take full advantage of:}

- Convenient online submission

- Thorough peer review

- No space constraints or color figure charges

- Immediate publication on acceptance

- Inclusion in PubMed, CAS, Scopus and Google Scholar

- Research which is freely available for redistribution

Submit your manuscript at www.biomedcentral.com/submit
C) Biomed Central 